\title{
Seasonal influenza vaccination in pregnant women: knowledge, attitudes, and behaviors in Italy
}

\author{
Francesco Napolitano, Paola Napolitano and Italo Francesco Angelillo*
}

\begin{abstract}
Background: The aims of this study were to assess the knowledge, attitudes, and behaviors towards seasonal influenza and its vaccination among pregnant women.

Methods: A cross-sectional survey was carried out among a sample of women in the second or third trimester of pregnancy in Italy.

Results: The $64.2 \%$ of the sample knew that the influenza is more dangerous for pregnant women. Women of older age, Italian, and who had a pregnancy at high-risk were more likely to have this knowledge. This knowledge was lower among women with none, primary or secondary school education. The majority of the respondents considered the vaccine not very useful during pregnancy. Those younger, unmarried, who knew that influenza is more dangerous for pregnant women, who knew that the vaccine could protect them, who reported a higher self-rated health status, and who had received information about influenza and its vaccination were more likely to have a positive attitude toward the usefulness of influenza vaccination in pregnancy. Women with secondary school education and with more than one child revealed a lower perception. Only $9.7 \%$ had received the vaccine and $21.4 \%$ of those unvaccinated would be willing to receive it. This positive attitude was higher among women with one child, who knew that the vaccine could protect them against the influenza, and who have a positive attitude toward the usefulness of the vaccination during pregnancy.
\end{abstract}

Conclusions: Health educational programs are needed to improve the knowledge about seasonal influenza and vaccination rate in pregnancy.

Keywords: Behaviors, Cross-sectional survey, Italy, Pregnant women, Seasonal influenza, Vaccination

\section{Background}

The seasonal influenza is one of the most frequent infections and pregnant women are at high risk with higher healthcare service use, morbidity and mortality especially in presence of chronic conditions [1-3].

The World Health Organization recommend the administration of the vaccine in healthy women who are, at the beginning of the influenza season, in the second or third trimester of pregnancy or with concomitant chronic conditions in any stage of gestation [2]. However, despite the availability of a safe and effective influenza vaccine for both the mother and the unborn [4-11], the vaccination

\footnotetext{
* Correspondence: italof.angelillo@unina2.it

Department of Experimental Medicine, Second University of Naples, Via Luciano Armanni, 5, 80138 Naples, Italy
}

rate in pregnant women is disappointingly low [12-15]. In Italy, the vaccination is recommended free of charge for those in the second and third trimester during the epidemic period [16].

Several studies have investigated the level of knowledge and the attitudes among pregnant women about seasonal influenza and its vaccination [17-26] and this is extremely important in order to develop strategies to improve vaccination rates. Indeed, women with higher knowledge regarding the usefulness of the vaccination are more willing to receive the vaccine during pregnancy [27-29] and the uptake is influenced by the low perception of the risks related to influenza [17, 20,30,31]. To date, there has been very little research concerning the level of knowledge and behaviors regarding seasonal 
influenza and the associated factors among pregnant women in Italy [32]. Therefore, the present survey was performed to achieve two primary objectives. The first objective was to assess the knowledge, attitudes, and behaviors towards seasonal influenza and its vaccination among pregnant women in Italy, and the second was to evaluate the determinants of knowledge and attitudes towards influenza vaccination.

\section{Methods}

\section{Study setting and population}

A cross-sectional survey design has been used, recruiting women in the second or third trimester of pregnancy between December 2015 and February 2016 attending Obstetrics ambulatory centers in public non-teaching hospitals in the geographic area of Naples, Italy. A two stages cluster sampling strategy has been used. Firstly, from the list of all public non-teaching hospitals in Naples, two hospitals have been randomly selected. Then, from each hospital a random sample of pregnant women has been recruited. Sample size was estimated assuming an expected positive attitude towards willingness to receive the influenza vaccine during the pregnancy of 30\%, a confidence interval of $95 \%$, and an error of $5 \%$. The required sample was estimated in 370 pregnant women. In order to select a representative sample of the population, assuming a $10 \%$ non-response rate, the final sample size was 410 pregnant women.

\section{Procedure}

The director of the selected hospitals received a letter requesting permission to carry out the survey, clarifying the purposes, the methods of collecting information, and the anonymity and confidentiality of the data. Eligible pregnant women in the second or third trimester of pregnancy aged 18 years or older attending the selected ambulatories were approached by one of the investigators before the clinical consultation and they were asked to complete an anonymous, face-to-face interview. Prior the interview, pregnant women were given information about the aims of the study, details about the data collection instrument, the anonymity of the interview, and that the data would be treated with respect of privacy. Signed consent form from each participant was obtained prior to data collection. Data was collected in the waiting room of the ambulatory center. Participation was voluntary and no payment or incentives has been given.

\section{Instrument}

The face-to-face structured questionnaire [Additional file 1: Questionnaire] comprised the following five sections: (i) socio-demographic (age, educational level, marital status, number of children, employment status, medical history, self-rated health status) and pregnancy characteristics (number of pregnancies, parity, gravid, week of pregnancy); (ii) knowledge regarding influenza and its vaccination during pregnancy (risk of contract influenza, vaccination as preventive measure, vaccine recommendation, safety of the vaccine). Response options included "true," "false," or "do not know"; (iii) attitude towards the influenza and its vaccination during pregnancy (concern about contract influenza, usefulness of the vaccine, safety of the vaccine, intention for getting or not getting the vaccination). The attitudes were measured with a 10-point Likert scale ranging from 1 to 10; (iv) behaviors regarding influenza vaccination in previous or current pregnancy (whether or not they had received vaccination, whether or not they had received advice by the physicians to receive the vaccination). Response options included "yes" and "no", and for each response a choice from a list of reasons; (v) sources of information about influenza and its vaccination.

A pilot study was conducted with 25 pregnant women (not included in the final sample) to determine the comprehensibility of each question. The protocol was presented and approved by the Human Research Ethical Committee of the Second University of Naples.

\section{Statistical analysis}

The software Stata version 10.1 was used to perform all statistical analysis [33]. The first level of analysis comprised descriptive statistics of the main sociodemographic and pregnancy characteristics of the sample and of the different questions. The second level of analysis has been completed in two stages. Firstly, a bivariate analysis was carried out to assess the association between each independent variable and the different outcomes of interest using chi-square test for the categorical variables and Student's $t$-test for the continuous variables. Secondly, multivariate analysis was performed. Multivariate logistic regression analysis was conducted to identify independent characteristics associated with the following dichotomous outcome variables: knowledge that influenza is more dangerous for pregnant women compared to non-knowledge (Model 1) and positive attitude towards willingness to receive the influenza vaccine in pregnancy compared to non-positive attitude (Model 3). A multivariate linear regression analysis was performed for the continuous outcome variable positive attitude towards the usefulness of the influenza vaccine during pregnancy (Model 2). The following characteristics of each respondent were included in all models: age (continuous, in years), highest level of education (three categories: none or primary school $=0$; secondary school $=1$; college degree or higher $=2$ ), Italian nationality ( tus $($ single/separated $/$ divorced $/$ idowed $=0 ; \operatorname{married}=1$ ), number of children (none $=0$; one $=1$; more than one $=2$ ), having a high-risk pregnancy (no $=0$; yes $=1$ ), and having received information about influenza and its vaccination 
during pregnancy $($ no $=0$; yes $=1)$. Moreover, selfrated health status (continuous), knowledge that influenza is more dangerous for pregnant women than for those who are not pregnant (no $=0$; yes $=1)$, knowledge that the vaccine could protect pregnant women against influenza (no $=0$; yes $=1$ ), and perceive dangerous for the unborn if the women contract the influenza during pregnancy (continuous) were included in Models 2 and 3. Finally, positive attitude towards the usefulness of the vaccine during pregnancy (continuous) was included in Model 3.

A stepwise procedure was used to obtain the final models according with $p$ values for the variable inclusion and exclusion in the models respectively of $>0.2$ and $<0.4$. Odds ratios (ORs) and 95\% confidence intervals (CIs) were calculated in the multivariate logistic regression analysis, and standardized regression coefficients $(ß)$ were presented in the linear regression model. A two-tailed $p$-value of less than 0.05 was used to define statistical significance.

\section{Results}

Out of the 410 pregnant women selected, 372 consented to participate for an overall response rate of $90.7 \%$. The main socio-demographic and pregnancy characteristics of the sample are reported in Table 1 . The mean age was 29 years, two thirds (67.5\%) reported the secondary school as highest education, the large proportion was married, one third has at least one child, the average gestation was 27 weeks, the $12.9 \%$ had a high-risk pregnancy, and the mean self-rated health status value was 7.1.

When it was asked about the seasonal influenza and its vaccination, $64.2 \%$ of the sample correctly answered that the influenza is more dangerous for pregnant women than for non-pregnant, $40.9 \%$ that the vaccine could protect pregnant women, one in four that vaccination was recommended during pregnancy, while only $11.2 \%$ and $7.9 \%$ of them correctly answered that it was recommended in the second or third trimester of pregnancy (Table 2). Table 3 presents the multivariate logistic and linear regression analysis of factors that remained independently associated in the models. Women of older age $(\mathrm{OR}=1.07 ; 95 \% \mathrm{CI}$ 1.01-1.13), Italian ( $\mathrm{OR}=4.97 ; 95 \% \mathrm{CI} 1.64-15.09)$, and with a pregnancy at high-risk $(\mathrm{OR}=11.43$; $95 \%$ CI $2.22-$ 58.85) were more likely to know that influenza is more dangerous for pregnant women. Moreover, this knowledge, when college degree or higher education was chosen as reference category, was lower among those with none/primary school $(\mathrm{OR}=0.08 ; 95 \% \mathrm{CI}=0.02-0.36)$ or secondary school level of education $(\mathrm{OR}=0.11 ; 95 \% \mathrm{CI}=$ 0.04-0.28) (Model 1).

With regard to attitudes, women feel dangerous for them and for the unborn to contract the influenza during pregnancy with a mean value respectively of 7.1 and
Table 1 Characteristics of the sample of pregnant women

\begin{tabular}{|c|c|c|}
\hline Characteristics & Number & Percent \\
\hline Age (years) & $29.3 \pm 4.9(18-43)^{\mathrm{a}}$ & \\
\hline \multicolumn{3}{|l|}{ Italian Nationality } \\
\hline Yes & 333 & 89.5 \\
\hline No & 39 & 10.5 \\
\hline \multicolumn{3}{|l|}{ Educational level } \\
\hline None or primary school & 30 & 8.1 \\
\hline Secondary school & 251 & 67.5 \\
\hline College degree or higher & 91 & 24.4 \\
\hline \multicolumn{3}{|l|}{ Marital status } \\
\hline Married & 332 & 89.2 \\
\hline Other & 40 & 10.8 \\
\hline \multicolumn{3}{|l|}{ Employment status } \\
\hline Yes & 175 & 47.1 \\
\hline No & 197 & 52.9 \\
\hline \multicolumn{3}{|l|}{ Number of children } \\
\hline 0 & 176 & 47.3 \\
\hline 1 & 124 & 33.3 \\
\hline$>1$ & 72 & 19.4 \\
\hline Week of pregnancy & $26.7 \pm 7.4(14-39)^{\mathrm{a}}$ & \\
\hline \multicolumn{3}{|l|}{ Number of previous pregnancies } \\
\hline 0 & 173 & 46.5 \\
\hline$\geq 1$ & 199 & 53.5 \\
\hline \multicolumn{3}{|l|}{ High-risk pregnancy } \\
\hline No & 324 & 87.1 \\
\hline Yes & 48 & 12.9 \\
\hline Self-rated health status & $7.1 \pm 1.7(1-10)^{a}$ & \\
\hline
\end{tabular}

${ }^{\mathrm{a}}$ Mean \pm standard deviation (range)

7.3, out of a maximum score of 10. Despite these perceptions, the majority considered the influenza vaccine during pregnancy not very useful with an average value of 4.9 , and feels the vaccine potentially dangerous for their health (mean 6.7) or for the unborn (mean 7).

Table 2 Knowledge about influenza and its vaccination

\begin{tabular}{llc}
\hline & Number & Percent \\
\hline $\begin{array}{l}\text { The influenza is more dangerous for pregnant } \\
\text { women than for non-pregnant women }\end{array}$ & 239 & 64.2 \\
$\begin{array}{l}\text { The vaccine could protect pregnant women } \\
\text { against the influenza }\end{array}$ & 152 & 40.9 \\
$\begin{array}{l}\text { The influenza vaccine is recommended for } \\
\text { pregnant women }\end{array}$ & 89 & 23.9 \\
$\begin{array}{l}\text { The influenza vaccine is recommended in the } \\
\text { second trimester of pregnancy }\end{array}$ & 10 & 11.2 \\
$\begin{array}{l}\text { The influenza vaccine is recommended in } \\
\text { the third trimester of pregnancy }\end{array}$ & 7 & 7.9 \\
The influenza vaccine is safe during pregnancy & 40 & 10.7 \\
\hline
\end{tabular}

a Only for those who answered that the influenza vaccine is recommended for pregnant women 
Table 3 Multivariate logistic and linear regression analyses indicating associations between independent variables and the different outcomes

\begin{tabular}{|c|c|c|c|c|}
\hline Variable & OR & SE & $95 \% \mathrm{Cl}$ & $p$ value \\
\hline \multicolumn{5}{|c|}{$\begin{array}{l}\text { Model 1. Knowledge that influenza is more dangerous for pregnant } \\
\text { women (sample size = 372) }\end{array}$} \\
\hline \multicolumn{5}{|c|}{ Log likelihood $=-186.11, x^{2}=116.25(8 \mathrm{df}), p<0.0001$} \\
\hline \multicolumn{5}{|l|}{ Educational level } \\
\hline College degree or higher & $1^{a}$ & & & \\
\hline None or primary school & 0.08 & 0.06 & $0.02-0.36$ & 0.001 \\
\hline Secondary school & 0.11 & 0.05 & $0.04-0.28$ & $<0.001$ \\
\hline Having a high-risk pregnancy & 11.43 & 9.55 & $\begin{array}{l}2.22- \\
58.85\end{array}$ & 0.004 \\
\hline Italian nationality & 4.97 & 2.81 & $\begin{array}{l}1.64- \\
15.09\end{array}$ & 0.005 \\
\hline Age & 1.07 & 0.03 & $1.01-1.13$ & 0.011 \\
\hline $\begin{array}{l}\text { Having received information about } \\
\text { influenza and its vaccination }\end{array}$ & 1.65 & 0.44 & $0.97-2.79$ & 0.06 \\
\hline \multicolumn{5}{|l|}{ Number of children } \\
\hline 0 & $1^{\mathrm{a}}$ & & & \\
\hline 1 & 1.67 & 0.47 & $0.96-2.91$ & 0.07 \\
\hline Marital status & 0.63 & 0.28 & $0.26-1.53$ & 0.313 \\
\hline Variable & Coeff. & SE & $t$ & $p$ value \\
\hline \multicolumn{5}{|c|}{$\begin{array}{l}\text { Model 2. Positive attitude towards the usefulness of the influenza } \\
\text { vaccine in pregnancy (sample size }=372 \text { ) }\end{array}$} \\
\hline \multicolumn{5}{|c|}{$F(12,359)=14.54, p<0.0001, R^{2}=0.32 \%$, adjusted $R^{2}=0.3 \%$} \\
\hline Age & -0.09 & 0.02 & -3.54 & $<0.001$ \\
\hline $\begin{array}{l}\text { Having received information about } \\
\text { influenza and its vaccination }\end{array}$ & 1.06 & 0.23 & 4.57 & $<0.001$ \\
\hline $\begin{array}{l}\text { Knowledge that influenza is more } \\
\text { dangerous for pregnant women }\end{array}$ & 0.66 & 0.29 & 2.23 & $<0.001$ \\
\hline $\begin{array}{l}\text { Knowledge that the vaccine could } \\
\text { protect pregnant women against } \\
\text { influenza }\end{array}$ & 1.21 & 0.29 & 4.18 & $<0.001$ \\
\hline \multicolumn{5}{|l|}{ Educational level } \\
\hline College degree or higher & $1^{\mathrm{a}}$ & & & \\
\hline None or primary school & 0.91 & 0.58 & 1.58 & 0.115 \\
\hline Secondary school & -0.85 & 0.29 & -2.89 & 0.004 \\
\hline \multicolumn{5}{|l|}{ Number of children } \\
\hline 0 & $1^{\mathrm{a}}$ & & & \\
\hline$>1$ & -0.82 & 0.32 & -2.58 & 0.01 \\
\hline Marital status & -1.03 & 0.41 & -2.56 & 0.011 \\
\hline Self-rated health status & 0.15 & 0.07 & 2.15 & 0.033 \\
\hline Having a high-risk pregnancy & 0.74 & 0.38 & 1.94 & 0.053 \\
\hline $\begin{array}{l}\text { Perceive dangerous for the unborn if } \\
\text { the women contract the influenza } \\
\text { during pregnancy }\end{array}$ & 0.06 & 0.05 & 1.05 & 0.295 \\
\hline Italian nationality & 0.42 & 0.46 & 0.89 & 0.375 \\
\hline
\end{tabular}

Table 3 Multivariate logistic and linear regression analyses indicating associations between independent variables and the different outcomes (Continued)

\begin{tabular}{lccccc}
\hline Variable & OR & SE & $95 \% \mathrm{Cl}$ & $p$ value \\
Model 3. Positive attitude towards willingness to receive the influenza \\
vaccine in pregnancy (sample size =336)
\end{tabular}

Multivariate linear regression analysis showed that those younger, unmarried, who knew that influenza is more dangerous for pregnant women, who knew that the vaccine could protect pregnant women, who reported a higher selfrated health status, and who had received information about influenza and its vaccination were more likely to have a positive attitude toward the usefulness of influenza vaccination during pregnancy. Moreover, women with secondary school level of education, compared to those with a college degree or higher education, and those who have more than one child, compared to those with no children, revealed a lower perception towards the usefulness of vaccination during pregnancy (Model 2).

Only $9.7 \%$ of the women had received influenza vaccination and the most important reason for being vaccinated was the advice of the physician (88.9\%), whereas, for those unvaccinated the reasons most often mentioned were that they had not received information by physicians $(34.9 \%)$, fear that the vaccine would be harmful (32.2\%), and believed that the vaccine was not needed (26.7\%).

Among unvaccinated women, only $21.4 \%$ reported a positive intention regarding vaccination during pregnancy. 
Multivariate logistic regression analysis revealed that this positive attitude was significantly higher among those who had one $(\mathrm{OR}=2.41 ; 95 \% \mathrm{CI}=1.15-5.08)$ or more than one child ( $\mathrm{OR}=3.34 ; 95 \% \mathrm{CI}=1.29-8.67)$ compared to those with no children, who knew that the vaccine could protect pregnant women $(\mathrm{OR}=3.03 ; 95 \% \mathrm{CI}=1.35-6.77)$, and who have a positive attitude toward the usefulness of the vaccination during pregnancy $(\mathrm{OR}=1.35 ; 95 \% \mathrm{CI}=1.14-1.59)$ (Model 3). The most frequently selected reasons for the positive attitude were the recommendation by the physician (59.7\%), that the influenza could be harmful for them (15.9\%) and for the unborn baby (19.4\%). Reasons for unwilling to receive the vaccine included concerns for the unborn (65.4\%) or for the pregnant woman (63.1\%).

During their current pregnancy, only $40.3 \%$ had received information about influenza and its vaccination mainly by physicians (62\%), internet (32.1\%), and mass media (6.6\%). Moreover, the majority would like to learn more about influenza (59.9\%) and its vaccination $(61.6 \%)$.

\section{Discussion}

So far as we know, this is the first time that has been examined the level of knowledge, the awareness, and the behavior about seasonal influenza and its vaccination and also the associated factors in a large group of pregnant women in Italy.

It is important to consider that comparison with similar studies may be partly difficult due to differences regarding the study design, the study period, the strategies of the data collection, the different characteristics of the populations sampled, and the public health preventive activities. One of the main findings from this study is that the overall knowledge and the vaccination uptake were relatively poor. Indeed, less than two-thirds answered that the influenza is more dangerous for pregnant women than for non-pregnant, less than half that the vaccine could protect pregnant women, and one in four that the vaccination is recommended during pregnancy. When compared to other studies, the observed knowledge was higher. For example, in India none knew about influenza vaccination requirement during pregnancy [34], in Canada 36\% knew that influenza was more severe in pregnant women [35], in the United States $51 \%$ identified that seasonal flu is more dangerous for pregnant women and $54 \%$ that the seasonal flu shot is safe in pregnancy [17]. Similarly, in Australia 23\% of women believed that the vaccination during pregnancy was not safe and $30 \%$ that it would not protect them [19]. A considerably higher level of knowledge has been observed in the United States with $77 \%$ pregnant women who were aware that the vaccine is recommended [23] and in Pakistan $75 \%$ acknowledged that the vaccine is safe for pregnant women [24].
The present survey revealed a very low overall vaccination rate with a value of $9.7 \%$ and this of particular concern. In theory, one would expect that this group have a higher rate because of a better understanding of the need to be vaccinated. However, this is not observed in this sample. Therefore, it is important to design and to implement interventions in order to increase the vaccination rate. The value observed in the present study is higher than those reported in other countries, since no women had received influenza vaccination in the already mentioned study in India [34], 3\% in Turkey [36], 4\% in Thailand [26], and it is almost identical to the $6 \%$ in Iran [37], 10.9\% in Germany [38], and 16\% in Canada [39]. Whereas, it is substantially below the levels observed in Australia with an uptake of $27 \%$ [20], in France of $39 \%$ [40], in Belgium of $42.8 \%$ [41], and in the United States with levels ranging from $35 \%$ [14] to $66.4 \%$ [42]. One of the most commonly provided reasons by the unvaccinated was that their doctor had not discussed during their pregnancy. The finding that more than one third of those unvaccinated did not receive a health care provider recommendation is in line with previous studies [34, 36, 41, 43, 44]. Another commonly provided reason was the concern that vaccination may not be safe during pregnancy. Despite the extensive research demonstrating vaccine safety, this is alarming and this is accordance with previous studies $[14,17,20,40,43,45]$. This stressed the role of the physicians. Indeed, physicians are an important channel for reaching pregnant women and for delivering key messages in order to contribute to improve the acceptance of the vaccine. The finding regarding the sources of information about influenza, which might improve the level of knowledge and acceptance rate, showed that physicians were the deeply trusted source and this has been observed in previous studies [17, 21, 23, 36, 46]. Of the unvaccinated women, one-fifth indicated that they intended to receive the vaccination during pregnancy. This value is almost identical to the $21.6 \%$ found in the United States among pregnant minority women [47]. By contrast, higher values have been observed in the already mentioned survey in Thailand with $42 \%$ of the women who reported being willing to receive the seasonal influenza vaccine [26], in the United States $82.8 \%$ said they would be immunized if recommended by their physician [23], and in Pakistan $87 \%$ were willing to accept the vaccine [24].

Multivariate regression models have been developed for estimating the association of individual characteristics and specific outcomes of interest. Several socio-demographic characteristics, including age, educational level, and marital status, resulted significantly associated with greater knowledge and positive attitude. Women of older age had higher level of knowledge and, not surprisingly, those with 
higher education level were more likely to know that the influenza is dangerous for pregnant women and to report a positive attitude towards the utility of the vaccination during pregnancy. Prior study has shown similar findings [38]. The fact that women with a high-risk pregnancy were more likely to know that the influenza is dangerous for pregnant can serve as a focus when promoting health education interventions. Moreover, an association has been identified between knowledge concerning influenza and vaccination and the attitude toward the usefulness of the vaccination during pregnancy. Women with a better knowledge had a significantly higher likelihood of having a positive attitude toward the usefulness of the vaccination during pregnancy. Adequate knowledge and awareness of a disease are the key prerequisites for its prevention and control, given that adequate knowledge is a basis for adopting appropriate attitudes and practices.

Care is required in interpreting the findings of this study for potential limitations typical of populationbased questionnaire surveys. Firstly, it is difficult, as in the cross-sectional studies, to precisely determine temporal sequence between the dependent and independent variables. Secondly, there was a possibility of bias due to participants with favorable attitudes towards vaccination potentially being more likely to respond to the questionnaire. This suggests that responses can be biased due to forgetfulness or exaggeration of attitude and behaviors, social desirability, or affected by feelings at the time of the interview. Thirdly, the data were obtained from interviews and the answers were not verified through chart review and, therefore, it is not possible to be certain that the respondents answered correctly and recall bias could have occurred. Finally, a non-standardized questionnaire has been used, although this limitation has been partially solved by piloting the questions on a group of pregnant women. Despite the mentioned limitations, the major strength of the study resides in the high response rate, making the results robust enough to be representative of the population.

\section{Conclusions}

In conclusion, the low rate of vaccination and of women who have expressed a positive attitude towards to receive the vaccine support the need to develop health educational programs in order to improve the level of knowledge about seasonal influenza and its vaccination in this population focusing on the efficacy and safety. Gynecologists and primary care physicians, who are the providers of health care during pregnancy, with their consultations and recommendations should play a more substantial role in promoting this vaccination and to increase the uptake in pregnant women.

\section{Additional file}

Additional file 1: Questionnaire. (DOCX $48 \mathrm{~kb}$ )

\section{Abbreviations \\ $\mathrm{Cl}$ : Confidence interval; OR: Odds ratio}

\section{Acknowledgements}

The research team would like to thank the staffs of the selected hospitals for their assistance during data collection. We are also grateful to the pregnant women who contributed their precious time.

\section{Funding}

This research did not receive any specific grant from funding agencies in the public, commercial, or not-for-profit sectors.

\section{Availability of data and materials}

Data and supporting materials associated with this study will be provided upon request by the corresponding author.

\section{Authors' contributions}

FN and PN participated in the design of the study, were responsible for the data collection, performed the statistical analysis and contributed to the interpretation; IFA the principal investigator, designed the study, was responsible for the data collection, statistical analysis and interpretation, and wrote the article.

\section{Competing interests}

The authors declare that they have no competing interests.

\section{Consent to publish}

Not applicable.

\section{Ethics approval and consent to participate}

The protocol was presented and approved by the Human Research Ethical Committee of the Second University of Naples. Signed consent form from each participant was obtained prior to data collection.

Received: 6 September 2016 Accepted: 20 December 2016

Published online: 09 January 2017

\section{References}

1. Rasmussen SA, Jamieson DJ, Uyeki TM. Effects of influenza on pregnant women and infants. Am J Obstet Gynecol. 2012;207:S3-8.

2. World Health Organization. Vaccines against influenza. WHO position paper. Wkly Epidemiol Rec. 2012:47:461-76.

3. Mertz D, Kim TH, Johnstone J, Lam PP, Science M, Kuster SP, et al. Populations at risk for severe or complicated influenza illness: systematic review and meta-analysis. BMJ. 2013;347:f5061.

4. Black SB, Shinefield HR, France EK, Fireman BH, Platt ST, Shay D. Effectiveness of influenza vaccine during pregnancy in preventing hospitalizations and out-patient visits for respiratory illness in pregnant women and their infants. Am J Perinatol. 2004:21:333-9.

5. Zaman K, Roy E, Arifeen SE, Rahman M, Raqib R, Wilson E, et al. Effectiveness of maternal influenza immunization in mothers and infants. $\mathrm{N}$ Engl J Med. 2008;359:1555-64. Erratum in N Engl J Med. 2009;360:648.

6. Jamieson DJ, Kissin DM, Bridges CB, Rasmussen SA. Benefits of influenza vaccination during pregnancy for pregnant women. Am J Obstet Gynecol. 2012;207:S17-20.

7. Munoz FM. Safety of influenza vaccines in pregnant women. Am J Obstet Gynecol. 2012;207:S33-7.

8. Madhi SA, Cutland CL, Kuwanda L, Weinberg A, Hugo A, Jones S, et al. Influenza vaccination of pregnant women and protection of their infants. N Engl J Med. 2014;371:918-31.

9. Thompson MG, Li DK, Shifflett P, Sokolow LZ, Ferber JR, Kurosky S, et al. Effectiveness of seasonal trivalent influenza vaccine for preventing influenza virus illness among pregnant women: a population-based case-control study during the 2010-2011 and 2011-2012 influenza seasons. Clin Infect Dis. 2014;58:449-57. 
10. McMillan M, Porritt K, Kralik D, Costi L, Marshall H. Influenza vaccination during pregnancy: a systematic review of fetal death, spontaneous abortion, and congenital malformation safety outcomes. Vaccine. 2015;33:2108-17.

11. Marshall H, McMillan M, Andrews RM, Macartney K, Edwards K. Vaccines in pregnancy: the dual benefit for pregnant women and infants. Hum Vaccin Immunother. 2016;12:848-56.

12. Lu P, Bridges CB, Euler GL, Singleton JA. Influenza vaccination of recommended adult populations, U.S. 1989-2005. Vaccine. 2008:26:1786-93.

13. Henninger $M, C$ rane $B$, Naleway $A$. Trends in influenza vaccine coverage in pregnant women, 2008 to 2012. Perm J. 2013;17:31-6.

14. Ding $H$, Black $C L$, Ball S, Donahue S, Fink RV, Williams WW, et al. Influenza vaccination coverage among pregnant women-United States, 2014-15 influenza season. MMWR Morb Mortal Wkly Rep. 2015;64:1000-5.

15. European Centre for Disease Prevention and Control. Seasonal influenza vaccination in Europe. Overview of vaccination recommendations and coverage rates in the EU Member States for the 2012-13 influenza season. Stockholm: ECDC; 2015.

16. Ministero della Salute. Prevenzione e controllo dell'influenza: raccomandazioni per la stagione 2015-2016. http://www.salute.gov.it/ portale/news/p3_2_1_1_1.jsp? menu=notizie\&p=dalministero\&id $=2218$ Accessed 21 Dec 2016

17. Eppes C, Wu A, You W, Cameron KA, Garcia P, Grobman W. Barriers to influenza vaccination among pregnant women. Vaccine. 2013;31:2874-8.

18. Henninger M, Naleway A, Crane B, Donahue J, Irving S. Predictors of seasonal influenza vaccination during pregnancy. Obstet Gynecol. 2013;121: 741-9.

19. Taksdal SE, Mak DB, Joyce S, Tomlin S, Carcione D, Armstrong PK, et al. Predictors of uptake of influenza vaccination-a survey of pregnant women in Western Australia. Aust Fam Physician. 2013;42:582-6.

20. Wiley KE, Massey PD, Cooper SC, Wood NJ, Ho J, Quinn HE, et al. Uptake of influenza vaccine by pregnant women: a cross-sectional survey. Med J Aust. 2013:198:373-5

21. Bödeker B, Walter D, Reiter S, Wichmann O. Cross-sectional study on factors associated with influenza vaccine uptake and pertussis vaccination status among pregnant women in Germany. Vaccine. 2014;32:4131-9.

22. Maher L, Dawson A, Wiley K, Hope K, Torvaldsen S, Lawrence G, et al. Influenza vaccination during pregnancy: a qualitative study of the knowledge, attitudes, beliefs, and practices of general practitioners in Central and South-Western Sydney. BMC Fam Pract. 2014;15:102.

23. Healy CM, Rench MA, Montesinos DP, Ng N, Swaim LS. Knowledge and attitudes of pregnant women and their providers towards recommendations for immunization during pregnancy. Vaccine. 2015;33: 5445-51.

24. Khan AA, Varan AK, Esteves-Jaramillo A, Siddiqui M, Sultana S, Ali AS, et al. Influenza vaccine acceptance among pregnant women in urban slum areas, Karachi. Pakistan Vaccine. 2015;33:5103-9.

25. Ko HS, Jo YS, Kim YH, Park YG, Moon HB, Lee Y, et al. Knowledge, attitudes, and acceptability about influenza vaccination in Korean women of childbearing age. Obstet Gynecol Sci. 2015;58:81-9.

26. Ditsungnoen D, Greenbaum A, Praphasiri P, Dawood FS, Thompson MG, Yoocharoen $\mathrm{P}$, et al. Knowledge, attitudes and beliefs related to seasona influenza vaccine among pregnant women in Thailand. Vaccine. 2016;34 2141-6.

27. Fabry P, Gagneur A, Pasquier JC. Determinants of A (H1N1) vaccination: cross-sectional study in a population of pregnant women in Quebec. Vaccine. 2011;29:1824-9.

28. SteelFisher GK, Blendon RJ, Bekheit MM, Mitchell EW, Williams J, Lubell K, et al. Novel pandemic A (H1N1) influenza vaccination among pregnant women: motivators and barriers. Am J Obstet Gynecol. 2011;204:S116-23.

29. van Lier A, Steens A, Ferreira JA, van der Maas NAT, de Melker HE. Acceptance of vaccination during pregnancy: experience with 2009 influenza A (H1N1) in the Netherlands. Vaccine. 2012;30:2892-9.

30. Yudin MH, Salaripour M, Sgro MD. Impact of patient education on knowledge of influenza and vaccine recommendations among pregnant women. J Obstet Gynaecol Can. 2010;32:232-7.

31. Blanchard-Rohner G, Meier S, Ryser J, Schaller D, Combescure C, Yudin $\mathrm{MH}$, et al. Acceptability of maternal immunization against influenza: the critical role of obstetricians. J Matern Fetal Neonatal Med. 2012;25:1800-9.
32. Maurici M, Dugo V, Zaratti L, Paulon $L$, Pellegrini MG, Baiocco E, et al. Knowledge and attitude of pregnant women toward flu vaccination: a cross-sectional survey. J Matern Fetal Neonatal Med. 2015;15:1-4.

33. Stata Corporation. Stata Reference Manual Release 10.1. USA: College Station, TX; 2007.

34. Koul PA, Bali NK, Ali S, Ahmad SJ, Bhat MA, Mir H, et al. Poor uptake of influenza vaccination in pregnancy in northern India. Int J Gynaecol Obstet. 2014;127:234-7.

35. Halperin BA, MacKinnon-Cameron D, McNeil S, Kalil J, Halperin SA. Maintaining the momentum: key factors influencing acceptance of influenza vaccination among pregnant women following the H1N1 pandemic. Hum Vaccin Immunother. 2014;10:3629-41.

36. Celikel A, Ustunsoz A, Guvenc G. Determination of vaccination status of pregnant women during pregnancy and the affecting factors. J Clin Nurs. 2014;23:2142-50.

37. Honarvar B, Odoomi N, Mahmoodi M, Kashkoli GS, Khavandegaran F, Bagheri Lankarani $\mathrm{K}$, et al. Acceptance and rejection of influenza vaccination by pregnant women in southern Iran: physicians' role and barriers. Hum Vaccin Immunother. 2012;8:1860-6.

38. Bödeker B, Betsch C, Wichmann O. Skewed risk perceptions in pregnant women: the case of influenza vaccination. BMC Public Health. 2015;16:1308.

39. Legge A, Dodds L, MacDonald NE, Scott J, McNeil S. Rates and determinants of seasonal influenza vaccination in pregnancy and association with neonatal outcomes. CMAJ. 2014:186:E157-64.

40. Loubet P, Guerrisi C, Turbelin C, Blondel B, Launay O, Bardou M, et al. Influenza during pregnancy: Incidence, vaccination coverage and attitudes toward vaccination in the French web-based cohort G-GrippeNet. Vaccine. 2016:34:2390-6.

41. Laenen J, Roelants M, Devlieger R, Vandermeulen C. Influenza and pertussis vaccination coverage in pregnant women. Vaccine. 2015;33:2125-31.

42. Scheminske $M$, Henninger $M$, Irving $S A$, Thompson $M$, Williams J, Shifflett $P$, et al. The association between influenza vaccination and other preventative health behaviors in a cohort of pregnant women. Health Educ Behav. 2015; 42:402-8

43. Yuen CY, Dodgson JE, Tarrant M. Perceptions of Hong Kong Chinese women toward influenza vaccination during pregnancy. Vaccine. 2016;34: 33-40.

44. Lu PJ, Ding H, Black CL. H1N1 and seasonal influenza vaccination of U.S healthcare personnel, 2010. Am J Prev Med. 2012:43:282-92.

45. Maher L, Hope K, Torvaldsen S, Lawrence G, Dawson A, Wiley K, et al. Influenza vaccination during pregnancy: coverage rates and influencing factors in two urban districts in Sydney. Vaccine. 2013;31:5557-64.

46. Kharbanda EO, Vargas CY, Castaño PM, Lara M, Andres R, Stockwell MS. Exploring pregnant women's views on influenza vaccination and educational text messages. Prev Med. 2011;52:75-7.

47. Frew PM, Saint-Victor DS, Owens LE, Omer SB. Socioecological and message framing factors influencing maternal influenza immunization among minority women. Vaccine. 2014;32:1736-44.

\section{Submit your next manuscript to BioMed Central and we will help you at every step:}

- We accept pre-submission inquiries

- Our selector tool helps you to find the most relevant journal

- We provide round the clock customer support

- Convenient online submission

- Thorough peer review

- Inclusion in PubMed and all major indexing services

- Maximum visibility for your research

Submit your manuscript at www.biomedcentral.com/submit 